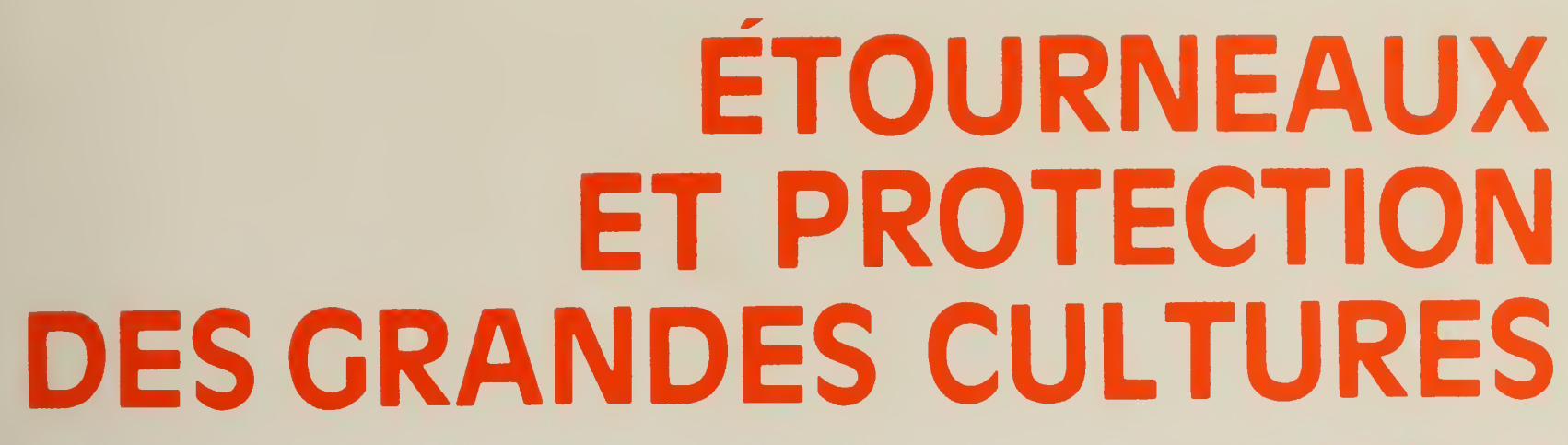

PUBLICATION 1652

2
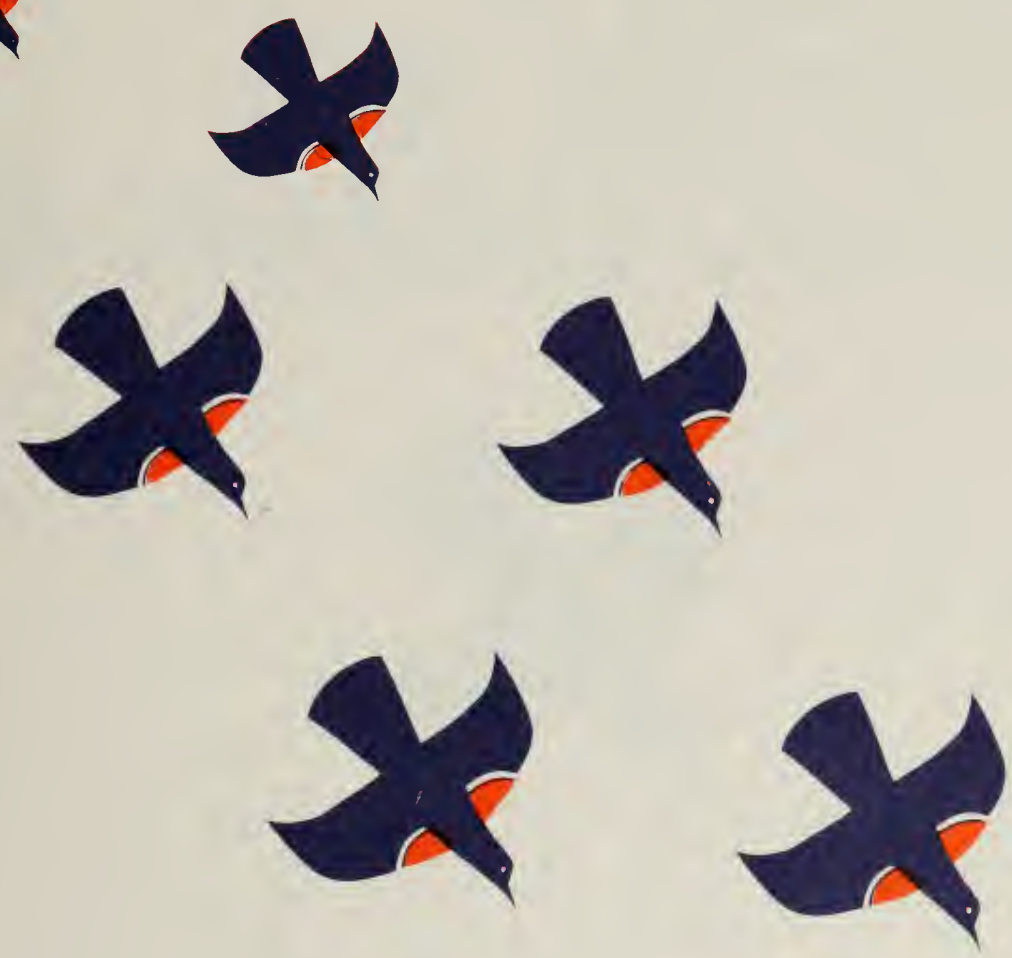

The Agriculture Canada

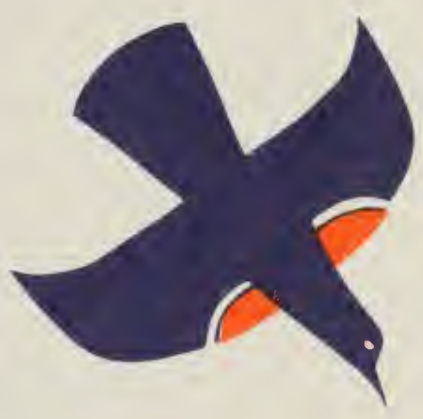

630.4

1212

P. 1652

1980

fr.

$c-3$ 



\section{ÉTOURNEAUX ET PROTECTION DES GRANDES CULTURES}

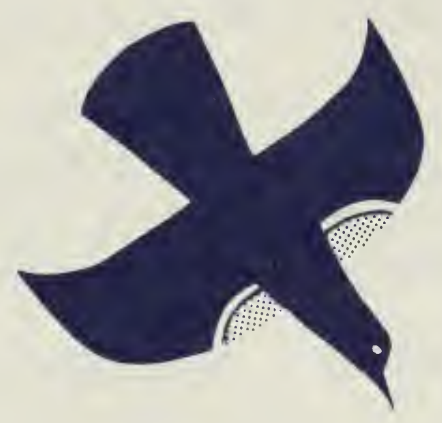

PUBLICATION 1652, on peut obtenir des exemplaires aux Services d'information, Agriculture Canada, Ottawa K1A OC7

(C) Ministre des Approvisionnements et Services Canada 1980 NO de cat. A53-1652!1980F Impression 1980 ISBN: 0-662-90589-X

Also available in English 


\section{INTRODUCTION}

Les étourneaux sont généralement plus utiles que nuisibles, mais ils causent parfois de sérieux ennuis à certains agriculteurs. Quand les champs de céréales, de tournesols ou de plantes potagères sont voisins des marais ou d'autres endroits attirants pour ces oiseaux, on les voit hanter les champs en grand nombre. Ils s'y nourrissent et causent des dommages considérables à l'orge, à l'avoine, au tournesol et au maïs, tant à l'état laiteux qu'à l'état pâteux.

Le carouge à épaulettes (Agelaius phœniceus) est l'espèce la plus répandue. Parmi les autres, mentionnons le carouge à tête jaune (Xanthocephalus xanthocephalus), le mainate à tête pourprée (Euphagus cyanocephalus) dans l'Ouest, le mainate bronzé (Quiscalus quiscula versicolor) et l'étourneau sansonnet (Sturnus vulgaris). Toutes ces espèces appartiennent à la famille des ictéridés, excepté l'étourneau sansonnet qui fait partie de la famille des sturnidés. A l'âge adulte, les mâles ont le corps noir tandis que les femelles ont un corps de ton plus terne ou brunâtre. Chaque espèce est reconnaissable à ses caractères particuliers.

\section{Espèces}

Carouge à épaulettes mâle

femelle

Carouge à tête jaune mâle

femelle

Étourneau sansonnet mâle et femelle

Mainate à tête pourprée mâle femelle

Mainate bronzé

Sexe tache rouge et jaune sur chaque aile

raies claires distinctes sur la poitrine

tête d'un jaune brillant et petite tache blanche sur chaque aile gorge et haut de la poitrine d'un jaune terne

queue plus courte, corps irisé (tacheté de blanc en automne), bec jaunâtre

yeux jaunâtres

yeux noirs

mâle et yeux jaunes, tête et corps irisés femelle et queue en forme de $U$ en plein vol 


\section{COMPORTEMENT}

Les étourneaux ne se propagent que dans un milieu propice à leurs besoins particuliers.

Les étourneaux nichent de préférence parmi les quenouilles, joncs et autres plantes croissant à proximité de l'eau. Les fossés en bordure des routes, les fosses-réservoirs, les marécages et les fondrières sont leurs lieux de prédilection. Si ces endroits sont dépourvus de végétation naturelle, ils se construisent un nid dans les champs de céréales ou de luzerne ou le long des clôtures envahies par les mauvaises herbes. Ces oiseaux ne se rassemblent pas en bandes nombreuses à l'époque de la nidification.

Après la période de nidification, les nichées se réunissent en volées auxquelles se joignent, en août et septembre, d'autres migrateurs venant de régions plus septentrionales. Les oiseaux se rassemblent dans les endroits où l'eau et la nourriture abondent.

Les étourneaux ont besoin de se jucher pour la nuit, de préférence à proximité de vastes étendues d'eau ou de marais ayant une végétation abondante de quenouilles, joncs, roseaux, carex ou saules. Parfois, ils installent leurs colonies près d'un ruisseau, parmi les hautes herbes et les arbustes. Tous les étourneaux des environs s'y rassemblent avant la tombée de la nuit. Au crépuscule, certaines volées font un arrêt dans des arbres ou dans les champs avant de regagner leur gîte principal.

Au lever du soleil, les oiseaux s'envolent en bandes, à la recherche de nourriture, dans un rayon d'une quinzaine de kilomètres. Ils choisissent un champ situé à proximité d'arbres et d'eau; ils y passent la journée à manger, à boire et à se reposer dans les arbres.

\section{ALIMENTATION}

Pour se renseigner sur le régime alimentaire des étourneaux, le regretté R.H. Bird (Ph.D.), de la station de recherches à Winnipeg, a étudié le contenu du gésier de centaines de sujets. Voici ses observations:

GLANURES DE GRAINS A leur retour au printemps et après la moisson, les étourneaux consomment de grandes quantités de glanures d'avoine, de blé et de tournesol. Ils se nourrissent de céréales qui viennent d'être mises en andains tant que les grains n'ont pas durci; après, ils préfèrent ramasser les grains humides tombés sur le sol. Ils ne touchent pas au lin, ni au mélilot, ni aux plantes fourragères.

MAUVAISES HERBES IIs sont friands des graines de mauvaises herbes, notamment celles de sétaire verte, de folle avoine et de renouée liseron lorsqu'ils en trouvent.

INSECTES Durant l'été, les étourneaux se nourrissent en grande partie d'insectes. Les oiselets sont exclusivement insectivores. Les étourneaux dévorent les insectes qui sont en grand nombre et qui 
s'attaquent aux récoltes, y compris les sauterelles, la tisseuse de la betterave, le charançon du mélilot, les pucerons des céréales, et bien d'autres.

CULTURES Quand une culture se trouve à proximité du lieu de rassemblement, les étourneaux peuvent endommager la graine, depuis son état laiteux jusqu'à sa maturation. Ils attaquent indistinctement l'orge, l'avoine, le blé, le maïs ou le tournesol. Dans les potagers, ils causent des dommages aux petits pois, mais non aux pois à soupe qu'ils ne visitent seulement qu'en quête d'insectes. Les étourneaux fréquentent les champs de tournesols déjà mûrs, mais surtout pour se nourrir des graines de mauvaises herbes et d'insectes. Ils causent des dégâts à l'avoine et, à un degré moindre, à l'orge et au blé en se posant sur les tiges debout, brisant ainsi les épis pour en extraire les grains.

En résumé, les habitudes alimentaires des étourneaux sont généralement bénéfiques pour l'agriculture, bien qu'elles puissent, à l'occasion, se révéler nuisibles pour quelques cultivateurs. A moins d'être protégées, diverses récoltes telles que l'avoine, le tournesol et le maïs sucré peuvent en souffrir particulièrement.

\section{PROTECTION}

Comme les étourneaux consomment en grandes quantités les graines de mauvaises herbes et les insectes nuisibles, il ne paraît guère avantageux de vouloir en réduire le nombre. Tout programme de destruction serait difficile et coûteux et devrait être répété chaque année puisque les oiseaux détruits seraient remplacés par d'autres la saison suivante. Il existe cependant divers moyens économiques et pratiques de protéger les cultures. L'idéal serait une combinaison des méthodes suivantes.

\section{Aménagement des récoltes}

Comme les dommages se produisent surtout à proximité des lieux de groupement que les étourneaux utilisent chaque année, on doit éviter d'y cultiver des récoltes particulièrement exposées. Si la chose est impossible on peut prendre les précautions suivantes:

- Aménager des aires d'alimentation pour les étourneaux; par exemple, éviter de cultiver toute la terre moissonnée tant que la récolte des plantes exposées n'est pas complètement terminée.

- Détourner les oiseaux de la récolte principale, tant qu'elle n'est pas moissonnée. A cette fin, semer de l'avoine tôt, en lisières étroites entre cette culture et le lieu de rassemblement des étourneaux. Les premières volées qui se forment après la nidification viendront d'abord s'y nourrir.

- A proximité des arbres où les étourneaux viennent gîter pendant le jour, cultiver des plantes qu'ils n'endommageront 
pas: le lin, les plantes fourragères, les pâturages, la betterave à sucre ou les pommes de terre. Si on doit semer des céréales dans ces champs, on les ensemence tôt, afin que la moisson soit presque terminée avant l'arrivée des bandes d'étourneaux.

\section{Engins d'effarouchement}

Si les dégâts ne peuvent être évités par un aménagement des cultures, on recourt à des engins spéciaux afin d'effaroucher les oiseaux pour les tenir à distance. Les méthodes suivantes sont efficaces si on commence à s'en servir avant que les oiseaux n'aient pris l'habitude de se nourrir dans un champ particulier. II faut persister dans l'emploi de ces mesures, de façon à ce que les étourneaux soient constamment tenus en alerte. Utilisés au petit bonheur, ces procédés sont une perte de temps et d'argent.

DÉTONATEURS Les détonateurs actionnés par l'allumage d'une faible quantité d'acétylène ou de propane à intervalles automatiquement réglables sont les plus efficaces. Un seul appareil peut protéger pour toute une saison jusqu'à 4 ha de cultures au coût d'environ $\$ 2,50 /$ ha. Dès que les oiseaux commencent à envahir le champ, on place ces détonateurs sur une plate-forme surélevée et près des arbres et des mares d'eau où les étourneaux vont gîter et boire. Régler la minuterie pour qu'il se produise une détonation à environ toutes les 2 minutes.

Plusieurs détonateurs peuvent être nécessaires dans un même champ. On doit les déplacer assez fréquemment pour que les oiseaux ne les associent pas à un endroit particulier.

Le détonateur produit plus d'effet lorsqu'il éclate par un trou pratiqué à un bout d'un petit tonneau métallique couché sur le côté. L'autre bout enlevé, le tonneau devient un amplificateur.

Si les étourneaux sont en train de se nourrir dans le champ au moment de l'installation des détonateurs, on les effraie d'abord par des coups de fusil. II est beaucoup plus difficile d'effrayer les oiseaux quand ils sont dans leurs gîtes nocturnes.

PÉTARDS Les pétards peuvent être utilisés si l'on veut éviter les frais d'achat ou de location d'un détonateur, ou si l'on n'a qu'un jardin ou un petit lopin de terre à protéger. Ils sont assez efficaces. Ils exigent cependant plus de précautions pour éviter de mettre le feu.

II vaut mieux acheter les gros pétards, de préférence ceux du type "bulldog". Enfiler les fusées dans un câble de coton qui se consume lentement, de façon à ce que les pétards éclatent à toutes les 5 minutes environ. Attacher les pétards ainsi enfilés à un poteau incliné audessus des cultures et les protéger contre le vent et la pluie au moyen d'un tuyau de poêle. Placer un seau sous le tuyau pour recevoir les pétards brûlants et éviter ainsi les risques d'incendie.

COUPS DE FUSIL Les coups de fusil effraient les oiseaux, mais ils constituent un exercice fastidieux car il s'agit surtout de les empêcher de revenir. Les cartouches à plomb coûtent plus cher et sont moins 
efficaces que celles de la carabine 0,22. Le sifflement de la balle dans l'air et à travers les cultures effraie les oiseaux. Si l'on tire d'une plateforme ou du haut d'un camion, il est possible de couvrir d'assez grandes superficies. Se rappeler toutefois que le tir d'une 0,22 porte jusqu'à $1,5 \mathrm{~km}$ et que les balles peuvent ricocher sur des objets durs. EPOUVANTAILS Les épouvantails sont les engins protecteurs les moins efficaces. A moins qu'on ne les change fréquemment de place, les oiseaux s'y habituent vite. Ils ont cependant un certain effet, s'ils sont combinés aux détonateurs.

\section{RENSEIGNEMENTS}

Pour de plus amples renseignements sur les étourneaux, consulter les services provinciaux suivants:

COLOMBIE-BRITANNIQUE: Direction des plantes cultivées, ministère de l'Agriculture de la Colombie-Britannique, édifices du Parlement, Victoria (C.-B.).

ALBERTA: Direction de la protection des récoltes et de la lutte contre les parasites, ministère de l'Agriculture de l'Alberta, édifice de l'Agriculture, Edmonton (Alb.).

SASKATCHEWAN: Services antiparasitaires, Direction des cultures industrielles, ministère de l'Agriculture de la Saskatchewan, édifice de l'Administration, Regina (Sask.).

MANITOBA: Section de l'entomologie, Direction des sols et cultures, ministère de l'Agriculture du Manitoba, édifice Norquay, Winnipeg (Man.).

ONTARIO: Service de biologie de l'environnement, Collège d'agriculture de l'Ontario, Université de Guelph, Guelph (Ont.).

QUÉBEC: Division de la défense des cultures, Agriculture Québec, complexe scientifique, parc Colbert, Québec (Québec).

NOUVEAU-BRUNSWICK: Le spécialiste de la protection des plantes, ministère de l'Agriculture et du Développement rural, Fredericton (N.-B.).

NOUVELLE-ÉCOSSE: Direction des sols et cultures, ministère de l'Agriculture et de la Commercialisation, édifice Hollis, Halifax (N.-É.).

ÎLE-DU-PRINCE-ÉDOUARD: Défense contre les parasites et les maladies, ministère de la Recherche et de la Vulgarisation agricoles, Charlottetown (Î.-P.-É.).

TERRE-NEUVE: Sols et cultures, ministère de l'Agriculture et des Forêts, édifice de la Confédération, Saint-Jean (T.-N.). 
Digitized by the Internet Archive in 2012 with funding from

Agriculture and Agri-Food Canada - Agriculture et Agroalimentaire Canada 



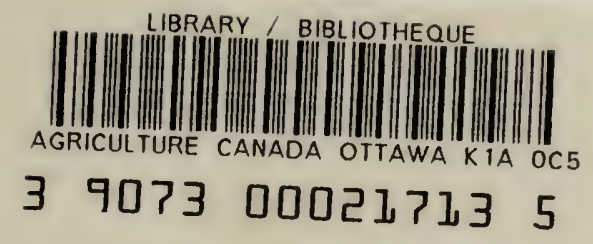


